\title{
Comparative Recoveries of Spaghetti Tags and Petersen Disc Tags on Atlantic Cod (Gadus morhua) and American Plaice (Hippoglossoides platessoldes)
}

\author{
G. Mark Fowler and Wayne T. Stobo \\ Marine Fish Division, Bedford Institute of Oceanography \\ Dartmouth, Nova Scotia, Canada B2Y 4 A2
}

\begin{abstract}
In two studies conducted in the Northwest Atlantic in 1979, the recovery rates of spaghetti tags were compared to those of Petersen disc tags. On the eastern Nova Scotian Shelf, 3,301 and 1,001 cod were tagged with spaghetti tags and Petersen discs, respectively. In the southern Gulf of St. Lawrence, 997 and 1,078 American plaice, respectively, were tagged. Over $98 \%$ of the recoveries from each species were made in the first 5 years following release. The spaghetti tag gave a significantly higher overall rate of recovery than the Petersen disc for cod $(0.235$ versus 0.158$)$. The spaghetti tag also gave a higher rate for American plaice $(0.098$ versus 0.094$)$, but the difference was not significant.
\end{abstract}

\section{Introduction}

Since its introduction in the early-1960s, the spaghetti tag (Dell, 1968) has become a popular external tag for finfish tagging studies. But few studies have assessed the recovery rate of this tag relative to other types of external tags, and the only three previous comparisons of Petersen disc tags and spaghetti tags have presented conflicting results. McDermott and Livingstone (1963) and Jensen (1963) obtained significantly higher recovery rates for haddock (Melanogrammus aeglefinus) marked with spaghetti tags than Petersen discs, while Hartt (1963) found the opposite for Pacific salmon (Oncorhynchus spp.).

Prior to 1978, tagging studies in the Northwest Atlantic on groundfish species primarily used the Petersen disc tag (Dickie, 1963; Gulland, 1963; Kelly and Barker, 1963; Kohler, 1963; MS 1975; Martin and Jean, 1964; Minet, MS 1976; Sandeman and Rees, 1963; Stobo et al., 1988; Templeman, 1979; Wise, 1963). Since 1978 , the spaghetti tag has largely superseded the Petersen disc, and several other less predominant tags, in NAFO Subarea 4 . This report examines the relative recovery rates of Petersen discs and spaghetti tags from experiments conducted in 1979 on Atlantic cod (Gadus morhua) and American plaice (Hippoglossoides platessoides).

\section{Methods}

In referring to tag types, we followed the definitions of spaghetti and Petersen disc tags as found in Jones (1979). Sequentially numbered spaghetti tags and Petersen disc tags were applied to cod and American plaice in two separate tagging studies (Table 1) conducted on the eastern Scotian Shelf and in the southern Gulf of St. Lawrence (Fig. 1). In the cod study, 2,000 more spaghetti tags than Petersen discs were applied because a large scale tagging program was being conducted at the same time to study the migration patterns of cod.

In both studies, the fish were caught by otter trawling with tow durations of $5-10 \mathrm{~min}$. per set, several tows being necessary to obtain adequate numbers of fish in each study. The short tow durations were intended to minimize stress and damage to the fish. Once on deck of the research vessel the fish were put into large tanks and placed in a V-shaped wooden trough where it was hand-held while being measured (total length) and tagged. For each species both tag types were applied to a portion of each set in order to ensure similarity in both tagging conditions and size of fish tagged (Table 1 ). The fish were then returned to the sea through a $19 \mathrm{~cm}$ diam. PVC pipe extending at about a $45^{\circ}$ angle from deck level to sea level; a continuous flow of salt water was maintained through the pipe to facilitiate fish movement down the pipe.

The spaghetti tags consisted of $8 \mathrm{~cm}$ lengths of yellow machine labelled No. 20 vinyl tubing attached to nylon T-bar anchors. A tagging gun ${ }^{1}$ was used to apply these near the base of the 2nd dorsal fin such that the T-bar would anchor itself between the interneural bones. In the case of cod the tag was applied in the area of the 2 nd dorsal fin while on American plaice it was applied close to the mid-point of the dorsal fin. The tags were inserted at an angle so that the exposed portion of

\footnotetext{
1 Tagging guns, and the spaghetti tags, were obtained from the Floy Tag Manufacturing Company, Seattle, Washington.
} 
TABLE 1. Releases of treatment groups for cod and American plaice tagging studies. Mean length of release groups given in parentheses.

\begin{tabular}{|c|c|c|c|c|c|c|}
\hline Species & $\begin{array}{l}\text { NAFO } \\
\text { Div. }\end{array}$ & $\begin{array}{c}\text { Release } \\
\text { dates }\end{array}$ & Tag type & $\begin{array}{c}\text { Number } \\
\text { of tags }\end{array}$ & $\begin{array}{l}\text { Length } \\
\qquad(\mathrm{Cr}\end{array}$ & $\begin{array}{l}\text { range } \\
\text { n) }\end{array}$ \\
\hline Cod & $4 T$ & 12-16 Apr 1979 & $\begin{array}{l}\text { Spaghetti } \\
\text { Petersen disc }\end{array}$ & $\begin{array}{l}3,301 \\
1,001\end{array}$ & $\begin{array}{l}24-111 \\
26-105\end{array}$ & $\begin{array}{l}(58.6) \\
(56.1)\end{array}$ \\
\hline $\begin{array}{l}\text { American } \\
\text { plaice }\end{array}$ & $4 T$ & $16-19$ Sep 1979 & $\begin{array}{l}\text { Spaghetti } \\
\text { Petersen disc }\end{array}$ & $\begin{array}{r}997 \\
1,078\end{array}$ & $\begin{array}{l}22-59 \\
23-64\end{array}$ & $\begin{array}{l}(34.6) \\
(35.1)\end{array}$ \\
\hline
\end{tabular}

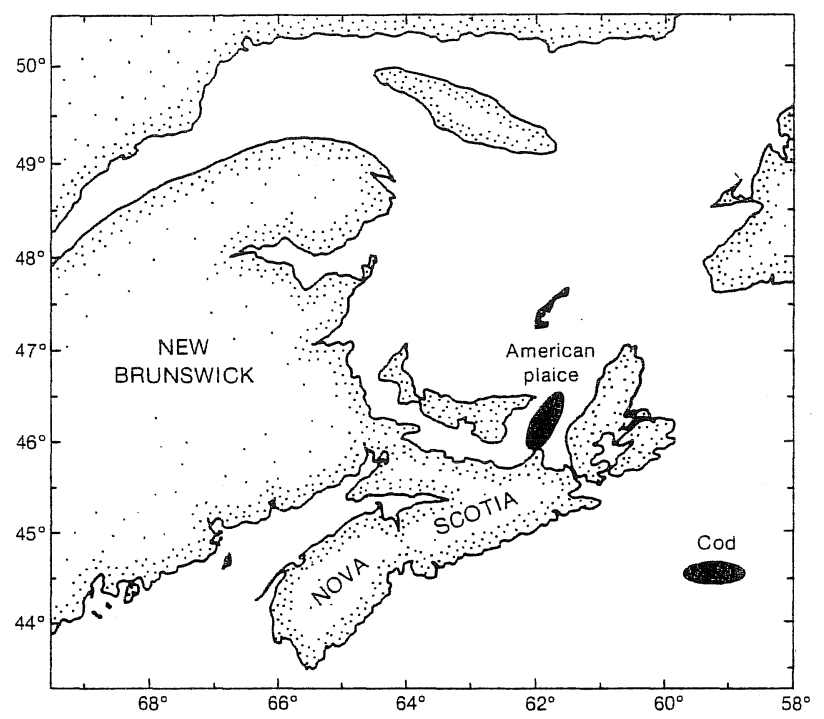

Fig. 1. Release locations for the comparative tag experiments on cod and American plaice.

the tag would lie close to the side of the fish, pointing posteriorly. The Petersen discs were also yellow (1.8 $\mathrm{cm}$ diam.) and placed in the same locations of each species. A thin stainless steel wire was passed through the dorsal musculature through a temporarily inserted hollow needle. The Petersen discs were then slipped over the ends of the wire on either side of the fish and attached by twisting each end of the wire with a pair of pliers. A reward was paid for each tag received, with recoveries made by fishermen and processing plant personnel.

Recoveries from 1979 to 1988 inclusive were used in this analysis. Overall recovery rates were calculated as the proportion of numbers recovered to numbers released. In calculating the recovery rate for a given year, recoveries made in previous years were first subtracted from total released in year one. It was assumed that the total recaptures of each species were completed by the end of 1988; there have been only 2 recoveries of the tagged cod since 1985, both in 1986, and only 2 recoveries of American plaice have been made since 1986, both in 1987.

The relative recovery rates of the two tag types were tested using the normal approximation to the dif- ference in binomial proportions (Malik and Mullen, 1973) with a critical value of $Z_{0.95}=1.98\left(H_{0}: P_{s}=P_{p}\right)$, where $Z$ is total mortality, $H_{0}$ is null hypothesis, $P_{s}$ is the proportion of spaghetti tag returns, and $P_{p}$ is the proportion of Petersen disc tag returns.

\section{Results and Discussion}

Both tags had a retention span on each species of more than 5 years but over 99 and $98 \%$ of the recoveries for cod and American plaice respectively were made during the first 5 years. Regardless of tag type a higher recovery rate was obtained for cod (0.217) than American plaice $(0.101)$, probably due to differences in the relative intensities of the fisheries. Catches in the directed cod fishery in Subdiv. 4 Vs during the 1978-82 period increased from 15,377 to 40,110 tons with associated fishing mortalities for age $3+$ fish ranging from 0.326 to 0.442 (Sinclair and Smith, MS 1987). Catches of American plaice in Div. 4T, however, declined steadily from 10,086 to 6,542 tons during the same period (Waite and Tallman, MS 1987). American plaice catches in the area have traditionally been a by-catch in the Div. 4T cod fishery, and no estimates of fishing mortality were available for the 1978-82 period. Given its status as a by-catch fishery, it seems likely that the exploitation rate on Div. 4T American plaice was lower than that for Subdiv. $4 \mathrm{Vs}$ cod.

Cod recaptures were 775 ( 0.235 recovery rate) with spaghetti tags and 158 (0.158 recovery rate) with Petersen discs, while American plaice recaptures were 98 (0.098 recovery rate) with spaghetti tags and 101 ( 0.094 recovery rate) with Petersen discs. A breakdown of recoveries and recovery rates by year (Table 2 ) demonstrate the differences between tag types over longer terms. Over $43 \%$ of cod tag recoveries of each tag type were made during the year of release $(8$ months at large), probably due to the intensive summer cod fishery in the area of release. Over $74 \%$ of the total recoveries had occurred by the end of 1980. Annual recoveries decreased steadily following the year of release, with the recovery rate for spaghetti tags declining more rapidly than that for Petersen discs. In all years, the recovery rate of cod tagged with spaghetti tags was higher than those with Petersen discs (Fig. $2 A)$ and overall, the spaghetti tag gave a significantly higher recovery rate $(Z=2.4, P<0.02)$. 
TABLE 2. Numbers of cod and American plaice recovered by year with year-specific recovery rates in parentheses. Yearly recovery rates are adjusted for numbers recovered in previous years.

\begin{tabular}{|c|c|c|c|c|c|c|}
\hline \multirow[b]{2}{*}{ Species } & \multirow{2}{*}{$\begin{array}{l}\text { Tag } \\
\text { type }\end{array}$} & \multicolumn{5}{|c|}{ Recoveries by year } \\
\hline & & 1979 & 1980 & 1981 & 1982 & $1983+$ \\
\hline Cod & $\begin{array}{l}\text { Spaghetti } \\
\text { Petersen }\end{array}$ & $\begin{array}{r}344(.104) \\
59(.059)\end{array}$ & $\begin{array}{r}244(.083) \\
52(.055)\end{array}$ & $\begin{array}{ll}98 & (.036) \\
22 & (.025)\end{array}$ & $\begin{array}{l}57(.022) \\
17(.020)\end{array}$ & $\begin{array}{r}32(.013) \\
8(.009)\end{array}$ \\
\hline $\begin{array}{l}\text { American } \\
\text { plaice }\end{array}$ & $\begin{array}{l}\text { Spaghetti } \\
\text { Petersen }\end{array}$ & $\begin{array}{r}14(.014) \\
5(.005)\end{array}$ & $\begin{array}{l}27(.028) \\
55(.051)\end{array}$ & $\begin{array}{ll}25 & (.026) \\
23 & (.023)\end{array}$ & $\begin{array}{r}15(.016) \\
5(.005)\end{array}$ & $\begin{array}{l}17(.019) \\
13(.013)\end{array}$ \\
\hline
\end{tabular}

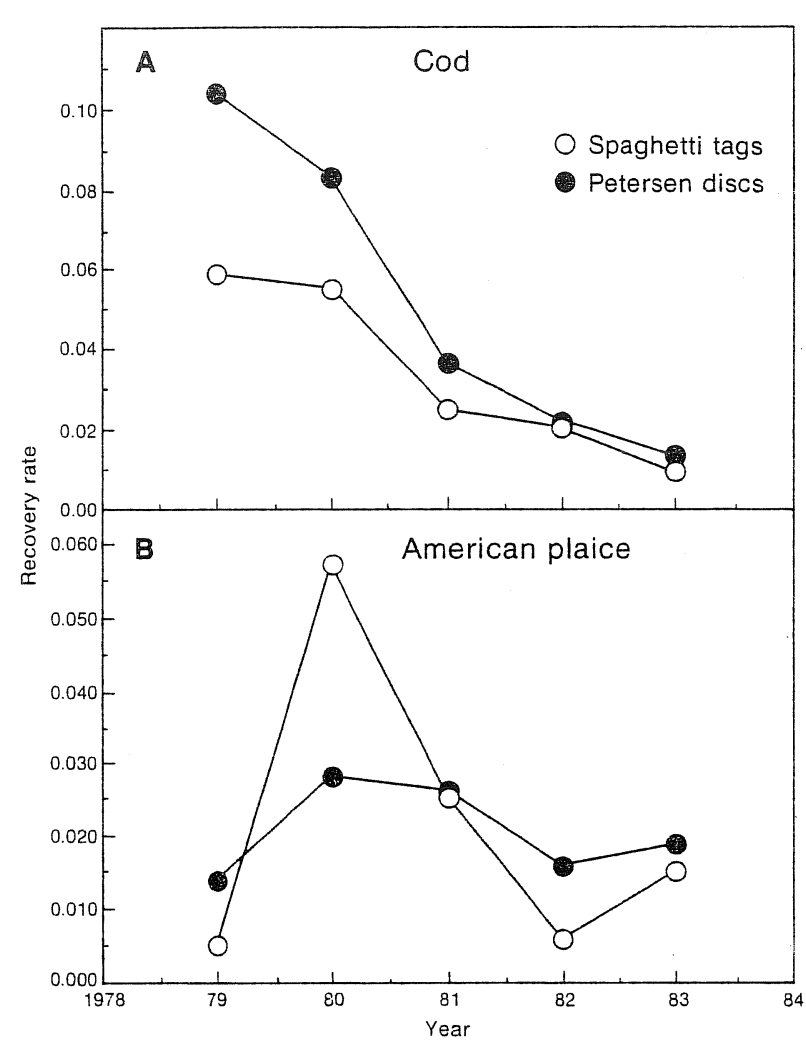

Fig. 2. Annual recovery rates of spaghetti tags and Petersen discs applied to cod and American plaice in 1979. Yearly recovery rates are adjusted for numbers recovered in previous years.

The experiment with American plaice occurred in September 1979. Since fishing effort for American plaice in Div. $4 T$ is quite low during the last few months of the year compared to the spring-summer period, relatively few recoveries were made in 1979. Consequently, the recovery rates for tagged American plaice in 1979 (Fig. 2B) appear anomalously low for both tag types relative to the other years. The largest percentage recovery for each tag type on American plaice occurred during 1980 and then, as with cod, declined steadily in subsequent years. Although the Petersen disc gave a marginally higher recovery rate than the spaghetti tag with American plaice, the difference was not significant $(Z=0.07)$.

The results for cod in this study are in accordance with those of both Jensen (1963) and McDermott and
Livingstone (1963) for another gadoid, haddock. The latter study provided data from which we derived recovery rates of 0.140 and 0.044 for spaghetti tags and dorsally applied Petersen discs respectively. McDermott and Livingstones' (1963) work involved several treatments; for our calculations we combined their damaged/undamaged fish subgroups to derive the overall recovery rate values. Jensen (1963), in two separate experiments, also demonstrated higher percent recoveries for spaghetti tags than for dorsally applied Petersen discs (12.9\% versus $2.5 \%$ and $14.9 \%$ versus $11.2 \%$, respectively). His data for haddock, although not explicitly stated, also support our observation for cod of a faster decline in the recovery rates of spaghetti tags than Petersen discs.

In contrast, Hartt (1963) obtained recovery rates for Pacific salmon in one study of 0.009 and 0.080 for spaghetti tags and Petersen discs ( $3 / 4^{\prime \prime}$ diam. red and white) respectively, while in a second study values of 0.126 and 0.137 were obtained. However, both studies relied on recoveries from gillnet fisheries, the first more so than the second. He surmised that the better Petersen disc recovery rate in the first study was due in large part to increased catchability of salmon resulting from the discs snagging in gillnets. Our studies, and those of Jensen (1963) and McDermott and Livingstone (1963) relied primarily on trawl fisheries for recoveries, a gear which is less likely to snag on tags. Hartt (1963) also obtained a much lower recovery rate $(0.013)$ using the $1 / 2^{\prime \prime}$ diam. white Petersen disc as opposed to the $3 / 4$ " diam. red and white tag and ascribed this difference to the reduced visibility of the smaller tags.

There is considerable variation in the magnitude of the difference in recovery rates between tag types across studies with gadoid fish. In our cod study, spaghetti tags were recovered at a rate 1.5 times that of Petersen discs, while in haddock studies, spaghetti tags have been recovered at rates of 1.3 and 5.2 (Jensen, 1963) and 3.1 (McDermott and Livingstone, 1963) times those of Petersen discs. We suspect this variation may be attributable to the smaller sample sizes in the haddock studies, which ranged widely from 179 to 572 releases per treatment.

With respect to the faster decline in recovery rates for spaghetti tags relative to Petersen discs, which were 
observed for cod in the current study and for haddock (Jensen, 1963), we can only speculate as to possible causes. Jensen (1963) found substantial variation in the visibility of different tags in a comparison between shipboard and plant processing procedures, which suggests that various aspects of commercial handling procedures could influence recovery rates. Alternatively, differential tag retention could influence recovery rates of different tags, since in the case of cod, consistent trends were observed (Fig. 2A). Such an explanation, however, could not apply to American plaice due to inconsistency in the recovery rate trends (Fig. 2B).

We conclude that for gadoids in general the spaghetti tag is preferable to the Petersen disc tag with respect to recovery rates, while for flatfish either tag may be suitable. However, it should be noted that the enhancing effect of Petersen discs on catchability in gillnets mitigates against their use in calculation of mortality rates in studies where such gear comprise a significant component of the fishery.

\section{Acknowledgements}

We thank Bill Smith for organizing and supervising the tagging trips and Irma Thompson for processing the tag recoveries and maintaining the tagging database. We are grateful to $\mathrm{Dr}$ S. Campana and $\mathrm{Mr} \mathrm{P}$. Fanning for their reviews and constructive comments on an earlier draft of the manuscript.

\section{References}

DELL, M. B. 1968. A new fish tag and rapid, cartridge-fed applicator. Trans. Amer. Fish. Soc., 97: 57-59.

DICKIE, L. M. 1963. Estimation of mortality rates of Gulf of St. Lawrence cod from results of a tagging experiment. ICNAF Spec. Publ., 4: 71-80.

GULLAND, J. A. 1963. The estimation of fishing mortality from tagging experiments. ICNAF Spec. Publ., 4: 218-227.

HARTT, A. C. 1963. Problems in tagging salmon at sea. ICNAF Spec. Publ., 4: 144-155.

JENSEN, A. C. 1963. Further field experiments with tags ion haddock. ICNAF Spec. Publ., 194-203.

JONES, R. 1979. Materials and methods used in marking experiments in fishery research. FAO Fish. Tech. Pap., No. 190

KELLY, G.F., and A. M. BARKER. 1963. Estimation of population size and mortality rates from tagged redfish, Sebastes marinus L., at Eastport, Maine. ICNAF Spec. Publ., 4: 204-209.

KOHLER, A. C. 1963. Use of tagging data in Subarea 4 cod growth investigations. ICNAF Spec. Publ., 4: 66-70.

MS 1975. Recoveries from 1969 cod tagging in ICNAF Subdivision 4Vn. ICNAF Res. Doc., No. 91, Serial No. 3570, 2 p.

MALIK, H. J., and K. MULLEN. 1973. A first course in probability and statistics. Addison-Wesley Publishing Company.

MARTIN, W. R., and Y. JEAN. 1964. Winter cod tagging off Cape Breton and on offshore Nova Scotia Banks, 1959-62. J. Fish. Res. Board Can., 21: 215-238.

MCDERMOTT, J. P., and R. LIVINGSTONE, Jr. 1963. Haddock tag returns in relation to fish condition. ICNAF Spec. Publ., 4: 216-217.

MINET, J. P. MS 1976. Migrations of cod between the northerr, Gulf of St. Lawrence and the southwestern banks of Newfoundland. ICNAF Res. Doc., No. 74, Serial No. 3886, 30 p.

SANDEMAN, E. J., and E. I. S. REES. 1963. Some notes on the tagging of redfish, Sebastes marinus (L.), from deep water. ICNAF Spec. Publ., 4: 300-305.

SINCLAIR, A., and S. J. SMITH. MS 1987. Assessment of 4VsW cod. CAFSAC Res. Doc., No. 72, 62 p.

STOBO, W. T., J. D. NEILSON, and P. G. SIMPSON. 1988. Movements of Atlantic halibut (Hippoglossus hippoglossus) in the Canadian North Atlantic. Can. J. Fish. Aquat. Sci., 45: 484-491.

TEMPLEMAN, W. 1979. Migration and intermingling of stocks of Atlantic cod, Gadus morhua, of the Newfoundland and adjacent areas from tagging in 1962-66. ICNAF Res. Bull., 14: 5-50.

WISE, J. P. 1963. Cod groups in the New England area. Fish. Bull. U.S., 63(1): 189-203.

WAITE, L., and R. F. TALLMAN. MS 1987. American plaice in NAFO Division 4T: a biological update. CAFSAC Res. Doc., No. 89, 22 p. 